\title{
Propagação vegetativa de seleções de porta-enxertos potencialmente tolerantes à morte-precoce do pessegueiro
}

\author{
Vegetative propagation of rootstock selections potentially tolerant to Peach Tree Short Life
}

\author{
Newton Alex Mayer ${ }^{{ }^{*}}$, Bernardo Ueno ${ }^{1} \&$ Tainá Rodrigues das Neves ${ }^{2}$ \\ ${ }^{1}$ Empresa Brasileira de Pesquisa Agropecuária, Pelotas, RS, Brasil. *Autor para correspondência: alex.mayer@embrapa.br. \\ ${ }^{2}$ Universidade Federal de Pelotas, Pelotas, RS, Brasil.
}

Submissão: 25/09/2017 | Aceite: 13/06/2018

\begin{abstract}
RESUMO
A morte-precoce do pessegueiro é uma síndrome cuja causa envolve diversos agentes bióticos e abióticos e, para reduzir os prejuízos, a principal linha de pesquisa tem sido a busca por porta-enxertos tolerantes. Dentre as características desejáveis em um bom porta-enxerto, a facilidade de propagação vegetativa é fundamental para preservação da identidade genética e facilitar a difusão de tecnologias. 0 objetivo, com o presente trabalho, foi avaliar a viabilidade técnica da propagação vegetativa por estacas herbáceas de 18 seleções clonais de porta-enxertos [Prunus persica (L.) Batsch.] potencialmente tolerantes à morte-precoce, sob câmara de nebulização intermitente. Como cultivares de referência, foram utilizadas 'Capdeboscq', 'Okinawa' (P. persica) e 'Sharpe' ['Chickasaw' (Prunus angustifolia Marsh.) x Prunus spp.]. Com as avaliações realizadas após 65 dias da estaquia, foi possível concluir que a propagação das seleções de porta-enxertos por estacas herbáceas é tecnicamente viável, com porcentagens de enraizamento que variaram de $21,67 \%$ a $91,67 \%$, de tal forma que nenhum desses genótipos deve ser descartado do processo de seleção. A qualidade das raízes adventícias formadas foi satisfatória na maioria dos genótipos estudados, com elevadas porcentagens de estacas aptas ao transplantio, satisfatório número e comprimento de raízes. Entretanto, a seleção WFM-ESM-07-04 e as cultivares Capdeboscq e Sharpe se destacaram positivamente nesse aspecto. Dentre os três portaenxertos de referência utilizados, 'Okinawa' e 'Capdeboscq' apresentaram capacidade propagativa (rendimento) por estacas herbáceas bastante similar entre si, porém ambos são melhores do que 'Sharpe'.
\end{abstract}

PALAVRAS-CHAVE: Rosaceae, Prunus spp., estacas herbáceas, câmara de nebulização intermitente.

\begin{abstract}
Peach Tree Short Life (PTSL) is a syndrome that involves several biotic and abiotic agents. Seeking to reduce losses, the main research line has been the search for tolerant rootstocks. Among desirable characteristics in an appropriate rootstock, the ease of vegetative propagation is fundamental to preserve genetic identity and facilitate the diffusion of technologies. The objective of this research was to evaluate the technical feasibility of vegetative propagation by herbaceous stem cuttings of 18 clonal rootstock selections [Prunus persica (L.) Batsch.], potentially tolerant to PTSL, under intermittent mist system. As reference rootstock cultivars, 'Capdeboscq', 'Okinawa' (P.persica) and 'Sharpe' ['Chickasaw' (Prunus angustifolia Marsh.) x Prunus spp.] were used. From the evaluations after 65 days of cutting set, it was possible to conclude that the propagation of rootstock selections by herbaceous cuttings is technically feasible, with rooting percentages varying from $21.67 \%$ to $91.67 \%$; thus, none of these genotypes should be discarded from the selection process. The quality of the adventitious roots formed was satisfactory in most of the studied genotypes, with high cuttings percentage suitable for transplanting, satisfactory root number and root length. However, the selection WFM-ESM-07-04 and cultivars Capdeboscq and Sharpe stood out positively in this aspect. Among the three reference rootstocks, 'Okinawa' and 'Capdeboscq' showed very similar propagative capacity (yield) for herbaceous cuttings, but both are better than 'Sharpe'.
\end{abstract}

KEYWORDS: Rosaceae, Prunus spp., herbaceous cutting, intermittent mist system.

\section{INTRODUÇÃO}

A morte-precoce do pessegueiro é uma síndrome caracterizada por um colapso da copa dos 
pessegueiros no final do inverno (principalmente em julho e agosto) ou no início da primavera, acompanhada de injúrias provocadas pelo frio, parasitismo do nematoide anelado (Mesocriconema xenoplax), cancro bacteriano causado pela bactéria Pseudomonas syringae pv. syringae, cancro de Leucostoma spp. ou Cytospora spp.. São observadas a ocorrência de necroses e odor azedo na parte interna da casca das pernadas principais e ramificações, redução ou paralisação do crescimento, que provocam abortamento de gemas, brotação fraca e desuniforme, baixo pegamento de frutos, seca de ramos e pernadas e morte de parte ou de toda a copa da planta. Entretanto, o porta-enxerto das plantas sintomáticas normalmente permanece vivo (MAYER \& UENO 2012, CAMPOS et al. 2014). Plantas sintomáticas apresentam maior atividade de peroxidase nas gemas e nos ramos durante o inverno, além de maiores níveis populacionais de Mesocriconema xenoplax e Helicotylenchus spp. na rizosfera (MARAFON et al. 2009).

Os sintomas de morte-precoce do pessegueiro verificados no Rio Grande do Sul são idênticos aos observados no Sudeste dos Estados Unidos (estados da Carolina do Sul, Carolina do Norte e Geórgia), onde recebe o nome de "Peach Tree Short Life" (PTSL). Dentre os diversos fatores que predispõem as plantas à esta complexa síndrome, estudos comprovam que o porta-enxerto apresenta destacada influência na manifestação dos sintomas (OKIE et al. 1994a, BECKMAN et al. 1997a, BECKMAN et al. 1997b, REIGHARD et al. 1997, BECKMAN et al. 2002, BECKMAN et al. 2008). Após várias décadas de pesquisas sobre o tema, os prejuízos devidos à morte-precoce do pessegueiro no Sudeste dos Estados Unidos estão sendo drasticamente reduzidos com os lançamentos e uso comercial dos porta-enxertos 'Guardian ${ }^{\circledR}$ ' (OKIE et al. 1994b), 'Sharpe' (BECKMAN et al. 2008) e 'MP-29 ${ }^{\circledR}$ ' (BECKMAN et al. 2012). Desses três portaenxertos, apenas 'Sharpe' é de domínio público e, por ser germoplasma de grande interesse para a persicultura gaúcha, a Embrapa Clima Temperado recentemente introduziu essa cultivar no Brasil (MAYER \& UENO 2015).

Como a síndrome é complexa e envolve diversos fatores bióticos e abióticos, sendo alguns deles não controláveis e/ou de difícil reprodução (como condições climáticas e alguns aspectos físicos do solo), inevitavelmente, em alguma das etapas do processo de seleção ou de avaliação dos porta-enxertos, faz-se necessário a realização de avaliações em condição de campo com histórico de morte-precoce (OKIE et al. 1994a, OKIE et al. 1994b, BECKMAN et al. 2008, BECKMAN et al. 2012). Assim, esse histórico de morteprecoce do pessegueiro nas áreas de cultivo comercial, é levada em conta justamente no início do processo seletivo de porta-enxertos, na pesquisa conduzida no Rio Grande do Sul (MAYER et al. 2009). Embora a fonte e a natureza dos fatores que resultam em maior longevidade de porta-enxertos tolerantes em áreas com histórico de PTSL sejam desconhecidas e não relacionadas à resistência a Mesocriconema xenoplax, esses genótipos tolerantes parecem ser resultado da polinização cruzada que ocorreu durante diversos ciclos de polinização aberta, como o que deu origem ao porta-enxerto 'Guardian ${ }^{\circledR 1}$ (OKIE et al. 1994a).

No Rio Grande do Sul, estado onde a morte-precoce do pessegueiro se concentra no Brasil e provoca prejuízos econômicos, a maioria dos pomares são formados por mudas cujos porta-enxertos são obtidos a partir de misturas de caroços das indústrias conserveiras (resíduo da industrialização do pêssego), situação que provoca grande variabilidade genética e impede a identificação varietal dos porta-enxertos (MAYER et al. 2014a). Se por um lado essa situação não permite padronização dos sistemas radiculares das plantas, por outro lado pode-se usufruir desta variabilidade genética existente na primeira fase de um trabalho de seleção in situ, o que pode reduzir tempo e dispêndio de recursos na busca por fontes de tolerância ou resistência. Assim, baseando-se na pressão de seleção existente nas condições edafoclimáticas dos pomares comerciais gaúchos, a Embrapa Clima Temperado iniciou em 2007 um projeto de seleção clonal in situ de porta-enxertos potencialmente tolerantes à morte-precoce (MAYER et al. 2009) que, ao longo de sete ciclos de seleção e clonagem, permitiu o resgate e estabelecimento de 148 genótipos de interesse, os quais são mantidos em coleção.

A facilidade de propagação vegetativa é um dos critérios de seleção de porta-enxertos do gênero Prunus spp. (BECKMAN et al. 2008, PINOCHET 2010, BECKMAN et al. 2012, RUBIO-CABETAS 2012, INDREIAS 2013). Sabendo-se do efeito genético na capacidade de emissão de raízes adventícias em estacas, da condição fisiológica dos ramos e das plantas matrizes (HARTMANN et al. 2002, TWORKOSKI \& TAKEDA 2007, SULUSOGLU \& CAVUSOGLU 2010, OSTERC \& ŠTAMPAR 2011) e da necessidade de viabilizar um método prático para clonagem, faz-se necessário avaliar o potencial propagativo dessas seleções com uso de propágulos de plantas matrizes uniformemente manejadas, para se avançar no processo de seleção. Em vista do que foi exposto formulou-se, como hipótese, que existem diferenças entre as seleções quanto a capacidade propagativa por estacas herbáceas. $O$ objetivo, com o presente trabalho, foi avaliar a viabilidade técnica da propagação vegetativa por estacas herbáceas de 18 seleções clonais de 
porta-enxertos [Prunus persica (L.) Batsch.] potencialmente tolerantes à morte-precoce do pessegueiro, sob câmara de nebulização intermitente, utilizando-se, como referência, as cultivares 'Capdeboscq', 'Okinawa' (P. persica) e 'Sharpe' ['Chickasaw' (Prunus angustifolia Marsh.) x Prunus spp.].

\section{MATERIAL E MÉTODOS}

Plantas matrizes de porta-enxertos de pessegueiro ( $P$. persica), selecionadas nos ciclos 2007/2008 e 2008/2009 em pomares comerciais gaúchos com histórico de morte-precoce do pessegueiro (MAYER \& UENO 2012, CAMPOS et al. 2014), foram estabelecidas no inverno de 2009 na "Coleção Porta-enxerto de Prunus" na Sede da Embrapa Clima Temperado, em Pelotas,RS. Originalmente, em cada pomar comercial com histórico de morte-precoce onde as plantas foram selecionadas, realizava-se a decepa da copa abaixo do ponto de enxertia entre os meses de julho e setembro, para estimular a brotação de cada porta-enxerto de interesse. Cada cepa recebia a seguinte identificação: XXX-YYY-ANO-PLANTA, sendo XXX = iniciais do nome do produtor; $Y Y Y$ = iniciais da cultivar copa; $A N O$ = ano de realização da decepa; PLANTA = número da planta selecionada naquele ano. Em janeiro ou fevereiro subsequente, os ramos herbáceos eram coletados e levados à câmara de nebulização da Embrapa Clima Temperado para enraizamento, aclimatação e crescimento em citropotes, completando-se o ciclo bianual (MAYER et al. 2009). Em coleção mantida em condições de campo, foram estabelecidas uma ou duas plantas de cada clone selecionado (não enxertado), para formar as plantas matrizes e dar continuidade ao processo de seleção.

Para a realização do presente trabalho, utilizaram-se plantas matrizes de todas as seleções clonais provenientes dos ciclos 2007/2008 e 2008/2009, conforme listadas na Tabela 1. Como cultivares de referência, utilizaram-se três cultivares: a) 'Capdeboscq' ( $P$. persica), cultivar tipo indústria e que também foi bastante utilizada para formar porta-enxertos até a década de 1980, no Sul do Brasil (MAYER et al. 2014a); b) 'Okinawa' ( $P$. persica), cultivar de porta-enxerto mais utilizada no Sudeste do Brasil (MAYER et al. 2014a); c) 'Sharpe' ['Chickasaw' (Prunus angustifolia Marsh.) x Prunus spp.], cultivar de porta-enxerto tolerante ao PTSL (BECKMAN et al. 2008, MAYER \& UENO 2015).

Tabela 1. Identificação, espécie e local da seleção clonal ou origem de propágulos das cultivares utilizadas para formação de plantas matrizes. Pelotas,RS, 2017.

Table 1. Identification, species and location of the clonal selection or propagules origin of the cultivars used for the mother tree formation. Pelotas, Rio Grande do Sul, Brazil, 2017.

\begin{tabular}{|c|c|c|}
\hline $\begin{array}{l}\text { Identificação da seleção ou } \\
\text { cultivar }\end{array}$ & Espécie & Local da seleção clonal ou origem de propágulos \\
\hline WFM-ESM-07-01 & P. persica & Sta. Helena, $8^{\circ}$ distrito de Pelotas-RS \\
\hline WFM-ESM-07-02 & P. persica & Sta. Helena, $8^{\circ}$ distrito de Pelotas-RS \\
\hline WFM-ESM-07-03 & P. persica & Sta. Helena, $8^{\circ}$ distrito de Pelotas-RS \\
\hline WFM-ESM-07-04 & P. persica & Sta. Helena, $8^{\circ}$ distrito de Pelotas-RS \\
\hline MF-GRA-08-01 & P. persica & Rincão da Caneleira, Morro Redondo-RS \\
\hline MF-JUB-08-09 & P. persica & Rincão da Caneleira, Morro Redondo-RS \\
\hline JCB-SAA-08-11 & P. persica & Júlio de Castilhos, $8^{\circ}$ distrito de Pelotas-RS \\
\hline JCB-SAA-08-13 & P. persica & Júlio de Castilhos, $8^{\circ}$ distrito de Pelotas-RS \\
\hline JCB-PLA-08-15 & P. persica & Júlio de Castilhos, $8^{\circ}$ distrito de Pelotas-RS \\
\hline JCB-PLA-08-16 & P. persica & Júlio de Castilhos, $8^{\circ}$ distrito de Pelotas-RS \\
\hline COAS-SAA-08-17 & P. persica & Santa Eulália, $8^{\circ}$ distrito de Pelotas-RS \\
\hline COAS-AME-08-20 & P. persica & Santa Eulália, $8^{\circ}$ distrito de Pelotas-RS \\
\hline COAS-AME-08-22 & P. persica & Santa Eulália, $8^{\circ}$ distrito de Pelotas-RS \\
\hline COAS-AME-08-25 & P. persica & Santa Eulália, $8^{\circ}$ distrito de Pelotas-RS \\
\hline GGS-TUR-08-27 & P. persica & Rincão da Caneleira, Morro Redondo-RS \\
\hline GGS-TUR-08-30 & P. persica & Rincão da Caneleira, Morro Redondo-RS \\
\hline GGS-TUR-08-31 & P. persica & Rincão da Caneleira, Morro Redondo-RS \\
\hline FRM-AGA-08-55 & P. persica & Santa Helena, $8^{\circ}$ distrito de Pelotas-RS \\
\hline Capdeboscq & P. persica & Embrapa Clima Temperado, Pelotas-RS \\
\hline Okinawa & P. persica & Viveiro “Irmãos Kagi”, Atibaia-SP \\
\hline Sharpe & $\begin{array}{l}\text { ['Chickasaw' (P. angustifolia } \\
\text { Marsh.) x Prunus spp.] }\end{array}$ & Universidade da Flórida, Gainesville-FL, USA \\
\hline
\end{tabular}

Na primeira semana de agosto de 2015, as plantas matrizes de todas as seleções e cultivares (Tabela 1) sofreram poda drástica, objetivando estimular intensa e vigorosa brotação. Essa poda consistiu 
de corte (com serrote ou tesoura pneumática) de todas as pernadas das plantas, entre 1 e 1,2 $\mathrm{m}$ de altura do solo, além da poda de encurtamento (com tesoura de mão) dos ramos finos remanescentes. Tratos culturais de rotina, como controle de plantas daninhas, adubações e tratamentos fitossanitários, foram realizados. Transcorridos aproximadamente 120 dias da poda, nos dias 7 e 8 de dezembro de 2015, coletaram-se ramos herbáceos devidamente identificados de cada clone, com aproximadamente $1 \mathrm{~m}$ de comprimento, transportando-os rapidamente à câmara de nebulização intermitente para evitar desidratação. As estacas herbáceas foram preparadas padronizando-as pelo seu comprimento (com $12 \mathrm{~cm}$ de comprimento), com corte apical em bisel, para facilitar o escorrimento da água, e transversal na base da estaca. Todas as folhas (entre três e seis folhas) dos dois ou três nós distais, em relação à base da estaca, permaneceram aderidas à estaca e foram cortadas ao meio e, na parte basal, as folhas e pecíolos foram removidos. Após o preparo, todas as estacas foram tratadas com solução hidroalcoólica $(50 \%$, v/v) de ácido indolbutírico (AIB), na concentração de $3.000 \mathrm{mg} \mathrm{L}^{-1}$, por cinco segundos (MAYER et al. 2009). As estacas não foram tratadas com nenhum produto fungicida ou bactericida, seja no preparo ou durante o período de enraizamento.

Caixas plásticas (46 × $30 \times 10 \mathrm{~cm}$ ), com fundo perfurado (32 furos por caixa, com $11 \mathrm{~mm}$ de diâmetro), foram utilizadas como contentores para a vermiculita fina e umedecida, na qual as estacas foram acondicionadas. As caixas foram mantidas sobre bancadas de ferro de $1 \mathrm{~m}$ de altura, em câmara de nebulização intermitente, localizada dentro de uma estufa agrícola tipo arco $(24 \times 8 \mathrm{~m}$, com $3 \mathrm{~m}$ de pé direito) com teto de polietileno transparente e laterais com tela anti-insetos, sem controle de temperatura ou umidade relativa do ar. A câmara de nebulização foi composta por uma linha de nebulizadores (Tietze ${ }^{\circledR}$

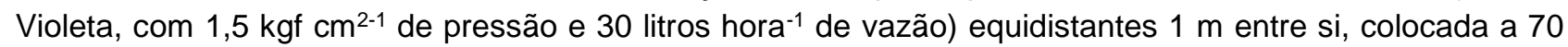
$\mathrm{cm}$ acima das caixas plásticas. Uma tela refletora Lumineti ${ }^{\circledR} 50 \%$ foi colocada a $1,2 \mathrm{~m}$ acima da linha de nebulizadores, para reduzir a radiação solar incidente. O sistema de nebulização intermitente foi programado por um timer para ser acionado por 10 segundos, a cada intervalo de 5 minutos, o que permitiu a manutenção de umidade constante sobre a superfície das folhas. Os tratamentos consistiram de 18 seleções de porta-enxertos potencialmente tolerantes à morte-precoce do pessegueiro, além das três cultivares de referência (Tabela 1), totalizando 21 tratamentos. O experimento foi instalado conforme delineamento inteiramente casualizado, com quatro repetições de 15 estacas por parcela, totalizando 84 parcelas.

Transcorridos 65 dias da instalação do experimento, avaliaram-se as seguintes variáveis: 1) porcentagem de estacas com folhas originais; 2) porcentagem de estacas brotadas. As estacas foram removidas manualmente das caixas e mergulhadas em água, para remoção da vermiculita aderida, sendo em seguida avaliadas e classificadas em uma das quatro variáveis a seguir: 3) porcentagem de estacas mortas; 4) porcentagem de estacas enraizadas mortas; 5) porcentagem de estacas com calo; 6) porcentagem de estacas enraizadas vivas. As estacas enraizadas vivas foram visualmente classificadas em: 7) porcentagem de estacas enraizadas aptas ao transplantio (MAYER et al. 2014b), ou seja, aquelas que apresentavam número mínimo de quatro raízes por estaca, adequadamente distribuídas ao redor da estaca; ou 8) porcentagem de estacas enraizadas inaptas ao transplantio, ou seja, aquelas estacas com três ou menos raízes, e/ou com inadequada distribuição ao redor da estaca (MAYER et al. 2014b). Em todas as estacas enraizadas vivas, foram também avaliados: 9) o número de raízes por estaca, por contagem; 10) o comprimento das três maiores raízes, avaliado com régua. As variáveis expressas em porcentagem foram transformadas para arc sen $\sqrt{x / 100}$, e as demais, não foram transformadas. Os resultados foram submetidos à analise de variância pelo teste $\mathrm{F}$ e as médias comparadas pelo teste de Scott-Knott, a 99\% de confiança, utilizando-se o software SASM - Agri (CANTERI et al. 2001).

\section{RESULTADOS E DISCUSSÃO}

Os dados relativos à porcentagem de estacas com calo não foram apresentados, pois dos 21 tratamentos testados, apenas seis seleções apresentaram alguma porcentagem de calo, o que resultou em elevado coeficiente de variação $(218,29 \%)$, na análise estatística. Além disso, nestas seis seleções que apresentaram formação de calo, as porcentagens foram desprezíveis em cinco delas (COAS-SAA-08-17, COAS-AME-08-20, COAS-AME-08-22 e COAS-AME-08-25, com 1,67\% de estacas com calo, e GGS-TUR08-27, com 2,5\% de estacas com calo) ou bastante baixa (13,24\%), na seleção FRM-AGA-08-55. O calo é definido como uma massa irregular de células do parênquima em vários estádios de lignificação que comumente se desenvolve na base das estacas acondicionadas em condições favoráveis ao enraizamento (HARTMANN et al. 2002). Em espécies e cultivares de fácil enraizamento adventício, a formação de calo e a formação de raízes são processos independentes (HARTMANN et al. 2002), o que tem sido verificado em 
estacas herbáceas ou semilenhosas do gênero Prunus spp. (CANLI \& BOZKURT 2009, MAYER et al. 2014b). A formação de calo também é reduzida com o uso do ácido indolbutírico na base das estacas, em espécies do gênero Prunus (MAYER et al. 2014b, MCMAHON et al. 2015).

Os dados de porcentagens de estacas mortas e de estacas enraizadas mortas são apresentados na Tabela 2. Na variável porcentagem de estacas mortas, ou seja, aquelas que morreram precocemente sem ter formado nenhuma raiz, com a análise estatística verificou-se a formação de dois grupos: o primeiro, com maior porcentagem (10 seleções e a cultivar Sharpe), cujos valores situaram-se entre 20 e $41,7 \%$ de estacas mortas, sem diferença estatística entre si; e um segundo grupo, contendo oito seleções e as cultivares Capdeboscq e Okinawa, com valores entre 3,25 e 16,67\%, também sem diferença estatística entre si. Um fator que contribuiu para essas elevadas porcentagens de mortalidade, sem a formação de raízes, foi a queda precoce das folhas originais das estacas. Estacas herbáceas sem suas folhas originais, na fase inicial do enraizamento, não realizam fotossíntese e, sem raízes ou brotações novas, morrem rapidamente (FRAGOSO et al. 2015). As folhas produzem carboidratos e hormônios naturais, como auxinas endógenas e cofatores do enraizamento, os quais são transferidos para a base das estacas por transporte polar, aumentando as concentrações na base propiciando melhores condições para a indução radicular (HARTMANN et al. 2002). Diversos são os fatores que podem contribuir para a queda das folhas durante 0 período de enraizamento adventício, sendo, às vezes, difícil diagnosticar a causa principal. Dentre esses fatores, pode-se mencionar a má nutrição da planta matriz, o balanço hormonal endógeno favorável a senescência das folhas, problemas fitossanitários, o estresse hídrico e a inadequada regulagem dos períodos de acionamento e de desligamento do sistema de nebulização, o estresse térmico, bem como o uso de substratos ou recipientes inadequados. Em estacas herbáceas com folhas, a adequada regulagem da câmara de nebulização intermitente é fundamental para evitar estresse e manter a eficiência fotoquímica das folhas (MATEJA et al. 2007). No presente trabalho, a presença de fungos do gênero Phomopsis sp. pode ter contribuído com a queda precoce das folhas originais das estacas, visto que não foi realizada a desinfecção prévia das estacas com fungicidas.

Tabela 2. Porcentagens de estacas mortas (\% EM), de estacas enraizadas mortas (\% EEM), de estacas enraizadas vivas (\% EEV), de estacas enraizadas aptas (\% EEA) e inaptas ao transplantio (\% EEI), aos 65 dias após a estaquia. Pelotas,RS, 2017.

Table 2. Percentage of dead cuttings (\% DC), dead rooted cuttings (\% DRC), alive rooted cuttings (\% ARC), suitable rooted cuttings (\% SRC) and unsuitable rooted cuttings (\% URC) for transplanting, at 65 days after cutting set. Pelotas, Rio Grande do Sul, Brazil, 2017.

\begin{tabular}{|c|c|c|c|c|c|}
\hline Tratamento - porta-enxerto & $\%$ EM & $\%$ EEM & $\%$ EEV & $\%$ EEA & $\% \mathrm{EEI}$ \\
\hline T01 - WFM-ESM-07-01 & $16,67 b$ & 43,33 a & $40,00 \mathrm{c}$ & $83,54 \mathrm{a}$ & $16,45 b$ \\
\hline T02 - WFM-ESM-07-02 & $21,67 \mathrm{a}$ & $40,00 \mathrm{a}$ & $38,34 \mathrm{c}$ & $78,04 \mathrm{a}$ & $21,97 \mathrm{~b}$ \\
\hline T03 - WFM-ESM-07-03 & $40,00 \mathrm{a}$ & $36,67 \mathrm{a}$ & $23,33 \mathrm{c}$ & $65,83 \mathrm{a}$ & $34,17 \mathrm{~b}$ \\
\hline T04 - WFM-ESM-07-04 & $13,33 b$ & $15,00 \mathrm{~b}$ & $71,67 b$ & $71,22 \mathrm{a}$ & $28,79 \mathrm{~b}$ \\
\hline T05 - MF-GRA-08-01 & $10,00 \mathrm{~b}$ & $6,67 \mathrm{~b}$ & $65,34 b$ & $83,98 \mathrm{a}$ & $16,03 b$ \\
\hline T06 - MF-JUB-08-09 & $25,00 \mathrm{a}$ & $10,00 \mathrm{~b}$ & $65,00 \mathrm{~b}$ & $36,17 b$ & $63,83 \mathrm{a}$ \\
\hline T07 - JCB-SAA-08-11 & $25,00 \mathrm{a}$ & $8,33 b$ & $66,67 \mathrm{~b}$ & $58,81 b$ & $41,19 \mathrm{a}$ \\
\hline T08 - JCB-SAA-08-13 & $20,00 \mathrm{a}$ & $8,33 \mathrm{~b}$ & $71,67 b$ & $75,10 \mathrm{a}$ & $24,90 \mathrm{~b}$ \\
\hline T09 - JCB-PLA-08-15 & $21,67 \mathrm{a}$ & $1,67 b$ & $76,67 \mathrm{~b}$ & $48,51 \mathrm{~b}$ & $51,50 \mathrm{a}$ \\
\hline T10 - JCB-PLA-08-16 & $6,67 \mathrm{~b}$ & $3,34 \mathrm{~b}$ & $90,00 \mathrm{a}$ & $83,54 \mathrm{a}$ & $16,47 \mathrm{~b}$ \\
\hline T11 - COAS-SAA-08-17 & $28,33 \mathrm{a}$ & $8,34 b$ & $61,67 \mathrm{~b}$ & $47,16 b$ & $52,84 \mathrm{a}$ \\
\hline T12 - COAS-AME-08-20 & $28,33 \mathrm{a}$ & $13,33 b$ & $56,67 \mathrm{c}$ & $66,46 a$ & $33,54 b$ \\
\hline T13 - COAS-AME-08-22 & $41,67 \mathrm{a}$ & $11,67 b$ & $45,00 \mathrm{c}$ & $57,86 \mathrm{~b}$ & $42,14 \mathrm{a}$ \\
\hline T14 - COAS-AME-08-25 & $26,67 \mathrm{a}$ & $15,00 \mathrm{~b}$ & $56,67 \mathrm{c}$ & $37,71 \mathrm{~b}$ & $62,29 a$ \\
\hline T15 - GGS-TUR-08-27 & $7,50 \mathrm{~b}$ & $5,00 \mathrm{~b}$ & $85,00 \mathrm{a}$ & $40,63 \mathrm{~b}$ & $59,38 \mathrm{a}$ \\
\hline T16 - GGS-TUR-08-30 & $13,33 b$ & $35,00 \mathrm{a}$ & $51,67 \mathrm{c}$ & $94,45 \mathrm{a}$ & $5,56 \mathrm{~b}$ \\
\hline T17 - GGS-TUR-08-31 & $16,67 b$ & $10,00 \mathrm{~b}$ & $73,34 b$ & $68,11 a$ & $31,89 \mathrm{~b}$ \\
\hline T18 - FRM-AGA-08-55 & $6,67 b$ & $6,67 b$ & $73,33 \mathrm{~b}$ & $49,73 b$ & $50,27 a$ \\
\hline T19 - Capdeboscq & $3,25 b$ & $5,00 \mathrm{~b}$ & $91,67 \mathrm{a}$ & $85,27 \mathrm{a}$ & $14,73 b$ \\
\hline T20 - Okinawa & $8,33 \mathrm{~b}$ & $8,34 \mathrm{~b}$ & $83,33 \mathrm{a}$ & $71,73 \mathrm{a}$ & $28,27 \mathrm{~b}$ \\
\hline T21 - Sharpe & $36,67 \mathrm{a}$ & $41,67 \mathrm{a}$ & $21,67 \mathrm{c}$ & $83,34 \mathrm{a}$ & $16,67 b$ \\
\hline $\mathrm{F}_{\text {porta-enxerto }}$ & $4,16^{\star \star}$ & $5,93^{* *}$ & $5,10^{* \star}$ & $3,79^{\star *}$ & $3,79^{\star *}$ \\
\hline $\mathrm{CV}(\%)$ & 37,29 & 49,20 & 22,51 & 22,59 & 38,22 \\
\hline
\end{tabular}

Duas seleções (WFM-ESM-07-02 e WFM-ESM-07-03) e a cultivar Sharpe, que apresentaram as mais altas porcentagens de estacas mortas, também encontraram-se dentro do grupo daquelas com as maiores porcentagens de estacas enraizadas mortas. Esta variável é importante e revela outra causa da morte das 
estacas, ou seja, o processo de rizogênese foi iniciado nas estacas, porém, devido à retenção de água pela vermiculita e/ou drenagem insuficiente, as estacas morreram. Com a soma das porcentagens dessas duas variáveis (mortas e enraizadas mortas), constata-se que os tratamentos que apresentaram as mais altas mortalidades totais foram: WFM-ESM-07-02 (61,67\%), WFM-ESM-07-03 (76,67\%) e a cv. Sharpe (78,34\%). Esses valores são considerados muito altos para propagação de acessos ou cultivares de pessegueiro, sob câmara de nebulização intermitente, e sugerem que o ambiente e o manejo adotado durante o período de enraizamento não foram os mais adequados, principalmente para esses três genótipos. Outros tratamentos, porém, apresentaram mortalidade total bastante baixa (valores menores do que 15\%), como nas seleções JCB-PLA-08-16, GGS-TUR-08-27, FRM-AGA-08-55 e na cv. Capdeboscq.

A análise da porcentagem de estacas enraizadas vivas, que é a variável mais importante em experimentos de propagação vegetativa via estaquia, revelou diferença estatística entre os tratamentos, que constituíram três grupos (Tabela 2). Duas seleções (JCB-PLA-08-16 e GGS-TUR-08-27) se destacaram, com $90 \%$ e $85 \%$ de estacas enraizadas vivas, respectivamente, as quais não diferiram significativamente de duas cultivares de referência: Capdeboscq (91,67\%) e Okinawa (83,33\%). Nove seleções encontraram-se no grupo intermediário (com valores entre 61,67 e $76,67 \%$, não diferindo estatisticamente entre si) e as demais sete seleções, juntamente com a cultivar Sharpe, encontraram-se no grupo daquelas com as menores porcentagens de estacas enraizadas vivas (valores entre 21,67 e 56,67\%). Segundo TWORKOSKI \& TAKEDA (2007) o enraizamento adventício varia entre cultivares de pessegueiro e hábitos de crescimento e essa variabilidade pode ser, em parte, devido a diferenças endógenas de hormônios. Para estacas herbáceas e semilenhosas de porta-enxertos do gênero Prunus spp., o uso de ácido indolbutírico, com doses entre 2.000 e $6.000 \mathrm{mg} \mathrm{L}^{-1}$, é fundamental para aumentar a porcentagem de estacas enraizadas, 0 número e o comprimento das raízes (SULUSOGLU \& CAVUSOGLU 2010, CARDOSO et al. 2011, MAYER et al. 2014b) e sua ação é rápida e ocorre nas primeiras 24 horas após a aplicação, sendo convertido para ácido indol-acético (IAA) (OSTERC \& ŠTAMPAR 2011).

Com relação à cultivar Sharpe, verificou-se que o uso de estacas herbáceas tratadas com $3.000 \mathrm{mg}$ $\mathrm{L}^{-1}$ de ácido indolbutírico resultou em baixa porcentagem de enraizamento (21,67\%) (Tabela 2). Esse resultado é bastante inferior ao obtido com estacas lenhosas sem folhas desta cultivar, também mantidas sob nebulização intermitente para preservação da hidratação das estacas, com as quais obteve-se $85 \%$ de enraizamento e satisfatório número de raízes por estaca (MAYER \& UENO 2015). MCMAHON et al. (2015) concluíram que a época do ano para a coleta e preparo das estacas e a dose de ácido indolbutírico foram fatores críticos para o sucesso do enraizamento da ameixeira 'Chickasaw' (Prunus angustifolia), um dos genitores de 'Sharpe'. Segundo os autores, estacas lenhosas com uma ou duas folhas, preparadas em maio ou agosto (hemisfério norte) a partir de ramos da estação de crescimento anterior, apresentaram os melhores resultados, com 44 e $49 \%$ de enraizamento, respectivamente, sendo necessário o uso do ácido indolbutírico com doses entre 3.000 e $7.000 \mathrm{mg} \mathrm{L}^{-1}$.

Para as variáveis porcentagens de estacas enraizadas aptas e inaptas ao transplantio, cuja soma resulta na porcentagem de estacas enraizadas vivas, observou-se diferença estatística significativa entre os tratamentos, que resultou na formação de dois grupos (Tabela 2). Como são variáveis complementares, os tratamentos que formaram o grupo daquelas com maiores porcentagens de estacas aptas ao transplantio (10 seleções e as três cultivares de referência), foram aquelas que formaram o grupo com as menores porcentagens de estacas inaptas ao transplantio. Essas duas variáveis revelam a qualidade visual do sistema radicular adventício formado e também é indicativo do rendimento de cada genótipo na fase de enraizamento e também da etapa subsequente: a aclimatação. As porcentagens de estacas aptas revelaram satisfatória qualidade das raízes para a maioria das seleções, visto que 12 das 18 seleções apresentaram porcentagens maiores do que 50\%, além das três cultivares de referência.

Outras duas variáveis que também revelam a qualidade das raízes adventícias são o número e o comprimento das raízes (Tabela 3). Em ambas as variáveis também houve diferença estatística entre os tratamentos, os quais formaram dois grupos distintos. Observando-se conjuntamente os dados dessas duas variáveis, constata-se que as seleções WFM-ESM-07-04 e JCB-SAA-08-11, bem como as cultivares Capdeboscq e Sharpe, são os únicos tratamentos que pertencem aos grupos com as maiores médias. Desses quatro tratamentos, WFM-ESM-07-04, Capdeboscq e Sharpe também encontraram-se no grupo com maior porcentagem de estacas aptas ao transplantio (Tabela 2), o que revela as melhores qualidades de raízes adventícias dentre todos os genótipos testados.

A análise da porcentagem de estacas com folhas originais revelou diferenças estatísticas significativas entre os tratamentos, os quais formaram quatro grupos (Tabela 3). No grupo com as maiores médias, encontram-se as seleções WFM-ESM-07-04, JCB-SAA-08-11, JCB-PLA-08-15, GGS-TUR-08-27 e 
a cv. Capdeboscq. A permanência das folhas originais da estaca é uma característica extremamente importante para o sucesso do enraizamento adventício sob câmara de nebulização. Verifica-se, nessas quatro seleções e na cv. Capdeboscq, que houveram baixas porcentagens de estacas enraizadas mortas (todas inferiores a 15\%) e, nas seleções WFM-ESM-07-04, GGS-TUR-08-27 e na cv. Capdeboscq, também baixas porcentagens de estacas mortas (todas inferiores a 13,33\%) (Tabela 2). Nos cinco tratamentos com as maiores porcentagens de estacas brotadas (Tabela 3), foram obtidas porcentagens de estacas enraizadas vivas entre 66,67 e 91,67\% (Tabela 2), porcentagens essas consideradas bastante satisfatórias, revelando a importância da permanência das folhas originais da estaca para o sucesso do enraizamento adventício.

Tabela 3. Número de raízes por estaca (NRE), comprimento das três maiores raízes (CR), porcentagem de estacas com folhas originais (\% EFO) e porcentagem de estacas brotadas (\% EB), aos 65 dias após a estaquia de cultivares e seleções de Prunus spp.. Pelotas, RS, 2017.

Table 3. Number of roots per cutting (NRC), length of the three largest roots (LLR), percentage of cutting with original leaves (\% COL) and percentage of sprouted cutting (\% SC), ), at 65 days after cutting set of cultivars and selections of Prunus spp.. Pelotas, Rio Grande do Sul, Brazil, 2017.

\begin{tabular}{|c|c|c|c|c|}
\hline Tratamento - porta-enxerto & NRE & $\mathrm{CR}(\mathrm{cm})$ & $\%$ EFO & $\%$ EB \\
\hline T01 - WFM-ESM-07-01 & $30,85 a$ & $9,94 \mathrm{~b}$ & $5,00 \mathrm{~d}$ & $50,00 \mathrm{c}$ \\
\hline T02 - WFM-ESM-07-02 & $23,18 \mathrm{a}$ & $6,66 \mathrm{c}$ & $5,00 \mathrm{~d}$ & $25,00 \mathrm{c}$ \\
\hline T03 - WFM-ESM-07-03 & $24,82 \mathrm{a}$ & $9,59 \mathrm{~b}$ & $6,67 d$ & $26,67 \mathrm{c}$ \\
\hline T04 - WFM-ESM-07-04 & $26,59 \mathrm{a}$ & $12,77 \mathrm{a}$ & $46,67 \mathrm{a}$ & $60,00 \mathrm{~b}$ \\
\hline T05 - MF-GRA-08-01 & $31,54 \mathrm{a}$ & $10,14 b$ & $35,00 \mathrm{~b}$ & $75,00 \mathrm{a}$ \\
\hline T06 - MF-JUB-08-09 & $10,22 \mathrm{~b}$ & $10,78 \mathrm{~b}$ & $40,00 \mathrm{~b}$ & $61,67 b$ \\
\hline T07 - JCB-SAA-08-11 & $20,25 \mathrm{a}$ & $13,26 \mathrm{a}$ & $53,33 a$ & $48,33 \mathrm{c}$ \\
\hline T08 - JCB-SAA-08-13 & $27,58 \mathrm{a}$ & $10,71 \mathrm{~b}$ & $10,00 \mathrm{c}$ & $73,34 \mathrm{a}$ \\
\hline T09 - JCB-PLA-08-15 & $18,54 \mathrm{~b}$ & $14,95 \mathrm{a}$ & $66,67 \mathrm{a}$ & $58,34 \mathrm{~b}$ \\
\hline T10 - JCB-PLA-08-16 & $38,04 \mathrm{a}$ & $11,18 \mathrm{~b}$ & $31,67 b$ & $71,67 \mathrm{a}$ \\
\hline T11 - COAS-SAA-08-17 & $8,47 \mathrm{~b}$ & $8,92 \mathrm{~b}$ & $15,00 \mathrm{c}$ & $40,00 \mathrm{c}$ \\
\hline T12 - COAS-AME-08-20 & $8,36 \mathrm{~b}$ & $10,70 \mathrm{~b}$ & $16,67 \mathrm{c}$ & $50,00 \mathrm{c}$ \\
\hline T13 - COAS-AME-08-22 & $7,14 \mathrm{~b}$ & $12,26 \mathrm{a}$ & $15,00 \mathrm{c}$ & $35,00 \mathrm{c}$ \\
\hline T14 - COAS-AME-08-25 & $7,76 \mathrm{~b}$ & $10,58 \mathrm{~b}$ & $20,00 \mathrm{c}$ & $31,67 \mathrm{c}$ \\
\hline T15 - GGS-TUR-08-27 & $8,58 \mathrm{~b}$ & $11,20 \mathrm{~b}$ & $55,00 \mathrm{a}$ & $43,33 \mathrm{c}$ \\
\hline T16 - GGS-TUR-08-30 & $16,46 \mathrm{~b}$ & $10,77 \mathrm{~b}$ & $18,33 \mathrm{c}$ & $50,00 \mathrm{c}$ \\
\hline T17 - GGS-TUR-08-31 & $13,44 b$ & $14,64 \mathrm{a}$ & $26,67 \mathrm{c}$ & $61,67 b$ \\
\hline T18 - FRM-AGA-08-55 & $9,00 \mathrm{~b}$ & $13,18 \mathrm{a}$ & $35,00 \mathrm{~b}$ & $66,67 \mathrm{~b}$ \\
\hline T19 - Capdeboscq & $23,12 \mathrm{a}$ & $12,43 \mathrm{a}$ & $60,00 \mathrm{a}$ & $88,33 \mathrm{a}$ \\
\hline T20 - Okinawa & $15,44 b$ & $13,72 \mathrm{a}$ & $28,34 \mathrm{~b}$ & $80,00 a$ \\
\hline T21 - Sharpe & $30,04 \mathrm{a}$ & $12,71 \mathrm{a}$ & $18,33 \mathrm{c}$ & $35,00 \mathrm{c}$ \\
\hline F porta-enxerto & $7,06^{\star \star}$ & $5,58^{\star *}$ & $10,95^{\star \star}$ & $5,97^{\star \star}$ \\
\hline CV (\%) & 37,65 & 14,61 & 26,41 & 20,18 \\
\hline
\end{tabular}

Médias seguidas por letras distintas na coluna diferem entre si pelo teste de Scott-Knott. ${ }^{*}$ significativo a $99 \%$ de confiança.

A porcentagem de estacas brotadas (Tabela 3) também revelou diferenças estatísticas entre os tratamentos, os quais formaram três grupos. Com as maiores porcentagens de brotação, destacaram-se as seleções MF-GRA-08-01 (75\%), JCB-SAA-08-13 (73,34\%), JCB-PLA-08-16 (71,67\%), e as cultivares Capdeboscq (88,33\%) e Okinawa (80\%). A capacidade de brotação das estacas do gênero Prunus spp. durante o enraizamento adventício sob câmara de nebulização intermitente é desejável, pois contribui para o processo fotossintético das estacas, fundamental para seu enraizamento. Além disso, ápices em crescimento, folhas jovens e gemas são locais de síntese de ácido indol-acético (IAA), uma auxina endógena que contribui para a formação de raízes adventícias (OSTERC \& ŠTAMPAR 2011). As três seleções e duas cultivares que apresentaram as maiores porcentagens de estacas enraizadas brotadas, observa-se que também se encontram no grupo das que apresentaram as maiores porcentagens de estacas enraizadas aptas ao transplantio, sendo todas com valores maiores que $71 \%$ (Tabela 2), ou seja, as novas brotações influenciam positivamente na qualidade das raízes. Assim, as novas brotações podem suprir a necessidade das estacas durante o enraizamento adventício, especialmente quando da queda de suas folhas originais.

Para futuros estudos com propagação de Prunus spp. por estacas herbáceas sob câmara de nebulização, sugere-se testar misturas de produtos para compor o leito de enraizamento, envolvendo vermiculita, perlita, casca de arroz carbonizada e outros produtos de fácil disponibilidade, como forma de 
ajustar melhor a retenção de ar e de água visando reduzir o encharcamento. A redução da frequência de ligamento noturno do sistema de nebulização intermitente e tratamentos com fungicidas nas plantas matrizes e/ou nas estacas também podem auxiliar na redução da mortalidade das estacas. Na continuidade do processo de seleção de porta-enxertos visando tolerância a morte-precoce do pessegueiro, os estudos deverão ser concentrados nas áreas de nematologia, estresses hídrico, físico e químico de solo, bem como avaliações dos porta-enxertos clonais em áreas com histórico da síndrome ao longo de vários anos.

\section{CONCLUSÃO}

Nas condições experimentais adotadas, foi possível concluir que:

- A propagação de seleções de porta-enxertos potencialmente tolerantes à morte-precoce do pessegueiro por estacas herbáceas sob nebulização intermitente é tecnicamente viável, com porcentagens de enraizamento que variaram de 21,67 a $91,67 \%$, de tal forma que nenhum desses genótipos deve ser descartado do processo de seleção;

- As seleções WFM-ESM-07-02 e WFM-ESM-07-03 e o porta-enxerto de referência 'Sharpe' apresentaram os piores desempenhos, com as mais altas porcentagens de mortalidade e as menores porcentagens de estacas enraizadas vivas;

- A qualidade das raízes adventícias formadas foi satisfatória na maioria dos genótipos estudados, com elevadas porcentagens de estacas aptas ao transplantio, satisfatório número e comprimento de raízes. Entretanto, a seleção WFM-ESM-07-04 e as cultivares Capdeboscq e Sharpe se destacaram positivamente nesse aspecto;

- Dentre os três porta-enxertos de referência utilizados, 'Okinawa' e 'Capdeboscq' apresentaram capacidade propagativa (rendimento) por estacas herbáceas bastante similar entre si, porém ambos são melhores do que 'Sharpe'.

\section{REFERÊNCIAS}

BECKMAN TG et al. 1997a. History, current status and future potential of Guardian ${ }^{\mathrm{TM}}$ (BY520-9) peach rootstock. Acta Horticulturae 451: 251-258.

BECKMAN TG et al. 1997b. The USDA-ARS stone fruit rootstock development program at Byron, Georgia. Acta Horticulturae 451: 237-242.

BECKMAN TG et al. 2002. Influence of scion and rootstock on incidence of peach tree short life. Acta Horticulturae 592: 645-648.

BECKMAN TG et al. 2008. 'Sharpe', a clonal plum rootstock for peach. HortScience 43: 2236-2237.

BECKMAN TG et al. 2012. 'MP-29', a clonal interspecific hybrid rootstock for peach. HortScience 47: 128-131.

CAMPOS AD et al. 2014. Morte precoce de plantas. In: RASEIRA MCB et al. (Ed). Pessegueiro. Brasília: Embrapa. p.509-530.

CANLI FA \& BOZKURT S. 2009. Effects of indolebutyric acid on adventitious root formation from semi-hardwood cuttings of 'Sarierik' plum. Journal Applied Biology Science 3: 45-48.

CANTERI MG et al. 2001. SASM - Agri: Sistema para análise e separação de médias em experimentos agrícolas pelos métodos Scott-Knott, Tukey e Duncan. Revista Brasileira de Agrocomputação 1: 18-24.

CARDOSO $\mathrm{C}$ et al. 2011. AIB e substratos no enraizamento de estacas de pessegueiro 'Okinawa' coletadas no outono. Semina: Ciências Agrárias 32: 1307-1314.

FRAGOSO R et al. 2015. Maintenance of leaves and indolebutyric acid in rooting of juvenile japanese flowering cherry cuttings. Revista Brasileira de Ciências Agrárias 10: 97-101.

HARTMANN HT et al. 2002. Plant propagation: principles and practices. 7.ed. New Jersey: Prentice Hall. 880p.

INDREIAS A. 2013. Breeding program of rootstocks for peach tree at the Research Station for Fruit Growing Constanta, Romania. Acta Horticulturae 981: 217-222.

MARAFON AC et al. 2009. Atividade da peroxidase durante o período hibernal de plantas de pessegueiro (Prunus persica (L.) Batsch.) cv. Jubileu com e sem sintomas da morte precoce. Revista Brasileira de Fruticultura 31: 938-942.

MATEJA $S$ et al. 2007. The effects of a fogging system on the physiological status and rooting capacity of leafy cuttings of woody species. Trees 21: 491-496.

MAYER NA \& UENO B. 2012. A morte-precoce do pessegueiro e suas relações com porta-enxertos. Pelotas: Embrapa Clima Temperado. 42p. (Documentos 359).

MAYER NA \& UENO B. 2015. 'Sharpe': porta-enxerto para pessegueiro introduzido no Brasil pela Embrapa Clima Temperado. Pelotas: Embrapa Clima Temperado. 27p. (Documentos 392).

MAYER NA et al. 2009. Seleção e clonagem de porta-enxertos tolerantes à morte-precoce do pessegueiro. Pelotas:

Embrapa Clima Temperado. 13p. (Comunicado Técnico 209).

MAYER NA et al. 2014a. Porta-enxertos. In: RASEIRA MCB et al. Pessegueiro. Brasília: Embrapa. p.173-223.

MAYER NA et al. 2014b. Estaquia herbácea de porta-enxertos de pessegueiro no final do verão. Semina: Ciências Agrárias 35: 1761-1772.

MCMAHON EA et al. 2015. Cutting and seed propagation of Chickasaw plum (Prunus angustifolia). International Journal 
of Fruit Science 15: 313-323.

OKIE WR et al. 1994a. Field-screening Prunus for longevity in the Southeastern United States. HortScience 29: 673-677. OKIE WR et al. 1994b. BY520-9 A peach rootstock for the Southeastern United States that increases scion longevity. HortScience 29: 705-706.

OSTERC G \& ŠTAMPAR F. 2011. Differences in endo/exogenous auxin profile in cuttings of different physiological ages. Journal of Plant Physiology 168: 2088-2092.

PINOCHET J. 2010. 'Replantpac' (Rootpac ${ }^{\circledR}$ R), a plum-almond hybrid rootstock for replant situations. HortScience 45 : 299-301.

REIGHARD GL et al. 1997. Field performance of Prunus rootstock cultivars and selections on replant soils in South Carolina. Acta Horticulturae 451: 243-249.

RUBIO-CABETAS MJ. 2012. Present and future trends in peach rootstock breeding worldwide. Acta Horticulturae 962 : 81-89.

SULUSOGLU M \& CAVUSOGLU A. 2010. Vegetative propagation of Cherry laurel (Prunus laurocerasus L.) using semihardwood cuttings. African Journal of Agricultural Research 5: 3196-3202.

TWORKOSKI T \& TAKEDA F. 2007. Rooting response of shoot cuttings from three peach growth habits. Scientia Horticulturae 115: 98-100. 